\title{
Numbers for Successful Poultry Production 1
}

\author{
Gary D. Butcher, DVM, Ph.D. and Amir H. Nilipour, Ph.D. ${ }^{2}$
}

Fertile egg production and incubation and production of broiler meat are both an art and a science. Man has taken full control of incubating fertile eggs by artificial means to supply the increasing world demand for poultry meat. It is estimated that worldwide more than 30 billion broiler fertile eggs are incubated annually. If eggs were still incubated naturally and broilers raised in small backyard farms, the poultry industry would not have been able to grow and prosper as it has and supply the world demand for poultry products. Table 1 demonstrates how poultry consumption in the US has increased dramatically in the last four decades, and the same pattern is also being seen in other countries. There is a considerable variation in consumption of poultry products among the various countries of the world ranging from 0.5 to 80 pounds per person. However, with the new economic reforms and the free trade zones being established among countries, consumer eating habits will likely change in favor of even greater increases in consumption of poultry products. The most practical manner of feeding the increasing human population, now growing at 100 million annually, is through producing even more high quality and economical protein sources, such as poultry meat and eggs. However, the production of these products even more effeciently and at a lower cost will need to be accomplished.
Table 1. Per capita consumption in USA

\begin{tabular}{|c|c|c|c|c|c|}
\hline Year & Poultry & Beef & Pork & Others & Total \\
\hline 1960 & 24.1 & 59.8 & 48.9 & 17.6 & 150.4 \\
\hline 1970 & 34.1 & 79.8 & 48.6 & 15.8 & 178.3 \\
\hline 1980 & 41.9 & 72.2 & 52.6 & 13.9 & 180.6 \\
\hline 1990 & 56.4 & 64.1 & 46.8 & 16.9 & 184.2 \\
\hline 1997 & 68.3 & 63.8 & 44.9 & 16.9 & 193.9 \\
\hline 1998 & 68.9 & 62.3 & 48.3 & NA & NA \\
\hline • Boneless equivalent weights, USDA, 1997 \\
-1997-1998 are projections
\end{tabular}

\section{The Most Efficient Survive}

World production of poultry meat and eggs in 1997 is estimated at 84 billion pounds of meat and more than 700 billion table eggs. More than $30 \%$ of the world's poultry meat is produced in the USA, while $50 \%$ of the world egg production is in China. It is important to consider that among the poultry producers in the USA, there exists considerable variation in the costs to produce a pound of meat or a dozen eggs. Table 2 shows the tremendous variation in total costs to produce a pound of broiler meat, varying from 32 to more than 38 cents.

In addition, table 3, compiled by Bell (Feedstuffs, Vol. 69, No. 49 Dec. 1, 1997), shows

1. This document is VM133, one of a series of the Veterinary Medicine-Large Animal Clinical Sciences Department, Florida Cooperative Extension Service, Institute of Food and Agricultural Sciences, University of Florida. Original publication date June 10, 2002. Visit the EDIS Web Site at http://edis.ifas.ufl.edu.

2. Gary D. Butcher, DVM, Ph.D., Diplomate, American College of Poultry Veterinarians, University of Florida College of Veterinary Medicine, Gainesville, FL., Amir H. Nilipour, PhD, Director of Investigation and Quality Assurance, Grupo Melo, S.A., Panama, Republic of Panama 
clearly the variation that exists among the egg producers in United States for about 400 flocks.

Table 2. Broiler production cost/lb.

\begin{tabular}{|c|c|}
\hline Category & Cents/lb. \\
\hline Best & 31.64 \\
\hline Worst & 38.41 \\
\hline Top 5\% & 31.87 \\
\hline Top 25\% & 32.43 \\
\hline Avg. & 34.22 \\
\hline
\end{tabular}

Table 3. Performance production variation of layers 21-60 weeks.

\begin{tabular}{|c|c|c|c|}
\hline Variable & $\begin{array}{c}\text { Best } \\
\mathbf{5} \\
\text { Flocks }\end{array}$ & $\begin{array}{c}\text { Poorest } \\
\mathbf{5} \\
\text { Flocks }\end{array}$ & $\begin{array}{c}\text { Average } \\
\mathbf{3 8 8} \\
\text { Flocks }\end{array}$ \\
\hline \# egg/hen housed & 244.2 & 196.2 & 221.3 \\
\hline \% Mortality & 1.3 & 15.9 & 5.5 \\
\hline $\begin{array}{c}\text { Consumption } \\
\text { (lbs/100 hens) }\end{array}$ & 18.2 & 24.4 & 21.3 \\
\hline Conversion & 2.79 & 3.80 & 3.16 \\
\hline
\end{tabular}

These dramatic differences in performance can be seen among farms in the same company and in the same region, utilizing the same feed and genetics. The only major difference is in the level of management skills among the growers. The calculation to quantitate losses when a poultry grower is not attentive to the economic consequences of good management is simple and is demonstrated in the following paragraph.

\section{5\% Efficiency Rate}

Due to variations in management, it is commonly noted that for every 100 fertile broiler eggs produced, only 50 to 75 eggs are actually converted to broiler meat. Losing between $25 \%$ to $50 \%$ of the total fertile eggs produced may seem dramatic, but it is a reality. However, these losses can be decreased if a poultry grower is willing to pay close attention to management details in an operation.

\section{Magic numbers}

From the time of oviposition until an egg is converted to meat, it goes through many processes. At each step there will be losses. These valuable fertile eggs are lost for many reasons, some acceptable and unavoidable, while others occur due to poor management. Each egg must be converted to at least to 2.0 kilos (or 4.4 pounds) of meat at 40 days of age under normal conditions. Thus each breeder hen should be able to produce at least 600 pounds of broiler meat during a 40 week production cycle. The difference between poultry managers who know what to expect in performance, including the limits and standards for each performance category, versus those managers who do not have an idea of what is going on in their operations is very obvious. If the performance results obtained are below expectations, the problem needs to be detected promptly and necessary corrective actions implemented. Tables 3 through 6 contain the basic, "rule of thumb" numbers for breeders, broilers and layers and should be committed to memory. These numbers could vary, however, depending on the operation and breeder types used.

\section{Breeder Performance}

The broiler breeder has experienced dramatic changes in the last few years and has primarily been selected for increased breast yield and more efficient feed conversion. Due to these selection pressures, the heavy breeders are now more sensitive to stressors. Their production performance and hatchability have been adversely affected when less than ideal conditions are provided in the farm. Table 4 provides the basic production parameters for review and evaluation of today's breeder.

Table 4. The 40-week production cycle ideal standards.

\begin{tabular}{|c|c|}
\hline Parameter & Expected result \\
\hline \# total fertile eggs produced/hen & $175-185$ \\
\hline$\%$ hen mortality & $<10 \%$ \\
\hline$\%$ male mortality & $<20 \%$ \\
\hline$\%$ egg production & $65 \%$ \\
\hline$\%$ of undergrade egg & less than $4 \%$ \\
\hline Average egg size & 65 grams \\
\hline$\%$ hatch & $84 \%$ \\
\hline
\end{tabular}

\section{Egg Size}

Depending on breeder age, the percent of hatch and egg size varies considerably. When visiting a breeder farm and lacking access to the egg weight standard table for the breed, which is the average 
compiled from weighing millions of fertile eggs, the following table may be used. To estimate the egg weight at any age, just add the Constant Egg Factor number as provided in the center column (table 5) to the hen's age. The egg weight calculated is not exact, but may serve as an accurate estimate during the on-farm investigation.

Table 5. The 40-week rule of thumb formula to calculate egg weight.

\begin{tabular}{|c|c|c|}
\hline $\begin{array}{c}\text { Week of age } \\
\text { period }\end{array}$ & $\begin{array}{c}\text { Egg } \\
\text { Factor }\end{array}$ & $\begin{array}{c}\text { Egg weight } \\
\text { range-gr. }\end{array}$ \\
\hline $25-35$ & 25 & $50-60$ \\
\hline $35-45$ & 20 & $60-65$ \\
\hline $45-55$ & 15 & $65-70$ \\
\hline $55-65$ & 10 & $70+$ \\
\hline
\end{tabular}

\section{Broiler Standards}

These vary considerably depending on the genetics, management practices, feeding program, health status, and climatic conditions, among other factors. The standards provided below in Table 6 are to be used for comparison purposes. The broilers off today have changed dramatically over the last couple of decades. With a good biosecurity program, optimum management/housing, and adequate nutrition, it is quite common to have broilers of more than 1.5 to 2.0 kilos at 35 days of age. Some geneticists predict that by the year 2005, broilers will reach 2.6 kilos in just 4 weeks! The modern broiler of today is gaining an average of 50 grams per day under current field conditions, but it is estimated that the same broiler has the genetic capability to double this rate of gain. This will only be possible when all factors needed for broiler growth are provided, such as optimum management, superior health, excellent environmental condition, and most important of all, an understanding of the nutritional requirements of the changing broiler. Table 6 provides the expected results for today's broiler raised under optimal conditions.

\section{The Commercial Layers}

These birds have literally come to the rescue of more than 2 billion undernourished people in the world. Table eggs provide an excellent nutritional package in places where there is deficiency of other protein sources, such as meat. A well managed and fed hen from a respected and known genetic line can easily produce more than 300 eggs in a 52-week production cycle. This is equivalent to 20 kilos of the best and most balanced food source that one can find and at a very reasonable price. Table 7 shows some of the basic standards expected from today's egg layer.

Table 6. The average broiler performance at 40 days of age.

\begin{tabular}{|c|c|}
\hline Parameter & Expected performance \\
\hline B. wt (1 day of age) & 45 \\
\hline B. Wt. (7 days of age) & 1 day of age weight X 4 \\
\hline First week \% mortality & Less than 0.70\% \\
\hline Body weight gr. & 2,000 \\
\hline Average daily wt. Gain g & 50 \\
\hline Conversion & 1.85 \\
\hline \% Total mortality & Less than 4\% \\
\hline EPEF index* & 260 \\
\hline $\begin{array}{l}\text { *European Efficiency Factor: gr. gained/day X \% } \\
\text { survival rate /Conversion X 10 }\end{array}$ \\
\hline
\end{tabular}

The above tables provide the poultry managers of today with some basic production numbers for poultry raised under optimal conditions. These standards should be used as a guide to let managers know how their birds are performing under local conditions versus established standards in other operations.

Table 7. The table hen production performance 52 weeks.

\begin{tabular}{|c|c|}
\hline Parameters & Expected performance \\
\hline \# eggs/hen & +300 \\
\hline$\%$ of cull eggs & $<5 \%$ \\
\hline Egg weight g & +60 \\
\hline Feed conversion LB/doz. & 3.4 \\
\hline Peak production & $+95 \%$ \\
\hline Weeks above 90\% & 15 \\
\hline$\%$ Mortality & $<5 \%$ \\
\hline
\end{tabular}

